\title{
A Method to Evaluate White Spruce Cone Crops
}

\section{R. F. Calvert}

\author{
Canadian Forestry Service \\ Petawawa Forest Experiment Station \\ Chalk River, Ontario
}

\begin{abstract}
The objective of this study was to investigate variation in cone size and seed production in Manitoba white spruce so that general guides to seed collection could be developed. Relationships were established using regression techniques which permitted the development of a three category cone crop classification system based on the probable yield of sound seed from cones. It is tentatively suggested to use this system, that the mean number of filled seed on one half of longitudinal cone sections be determined from a minimum of five to ten cones taken from all aspects of the top two to three $m$ of each of six to ten dominant or co-dominant trees. A crop quality rating is then determined by relating this to a graph which indicates a Good, Fair or Poor seed yield.
\end{abstract}

\section{Résumé}

L'auteur enquêta sur la variation dimensionnelle des cônes et la production de graines d'Epinette blanche du Manitoba afin de mettre au point un guide général de récolte des graines. L'auteur a établi des rapports au moyen de méthodes de régression, qui permirent l'élaboration de trois catégories de récoltes de cônes fondées sur le rendement probable de graines pouvant germer. L'utilisation de ce système exige que le nombre moyen de graines pleines sur un moitié des sections longitudinales des cônes soit déterminé à partir de cinq à dix cônes prélevés à moins de 2 à 3 mètres du sommet de chacun de six à dix arbres. II est alors possible d'évaluer la qualité de la récolte en comparant ce résultat à un graphique de rendement bon, passable ou médiocre.

\section{Introduction}

Collecting cones of coniferous timber species is a basic step in artificial regeneration programs. An annual requirement presents a problem because seed production in most species is irregular and in any one crop year enough seed must be collected to ensure the availability of seed until the next crop. It is thus desirable to collect cones whenever they are available in quantity and from locations which will produce the best-quality seed. Reliable methods are required which will identify good crops in advance of seed ripening to guide foresters in their collection programs.

Most cone collections in Canada are currently made without a good idea as to their actual seed yield. Decisions by field staff to collect cones are based usually on ocular estimates of cone abundance; i.e. crops are estimated by determining the frequency of trees bearing cones by crown classes; occasionally considering the length of the crown covered by cones. In some instances actual cone counts are made (Seal et al. 1965). More recently Eis and Inkster (1972) proposed a method of detecting potential cone crops in white spruce
(Picea glauca (Moench) Voss) based on a cumulative count of female buds from a specific branch taken from dominant or co-dominant trees in the fall or winter before the crop year. Values obtained are related to a sequential sampling scheme which enables the classification of the cone crop on a one-to-five scale. These methods of crop evaluation are satisfactory but do not estimate seed yield because an unfavourable environment during critical stages of bud development, pollination, or seed formation, or the occurrence of cone and seed destroying fungi and insects may significantly reduce a forecasted good crop.

The timing of collections is very important for maximum seed yield and quality. The most accurate way to appraise seed ripeness before it is shed is to slice the cone longitudinally and examine the sectioned seed on the cut surface; ripe seeds being those that are firm and white in colour (U.S. Forest Service 1974). A count of the number of full seed on a sectioned cone surface has been used to classify crops in a general way (Seal et al. 1965; Meagher 1974, Dobbs et al. 1976) and is used in combination with some other method of appraisal. It would be useful if counts of sound seed could be related to the yield of sound seed from cones to give the forester a more quantitative measure on which to base his decision to collect or not to collect them.

The objective of this study was to investigate the variation in cone size and seed production in white spruce in Manitoba so that general guides to seed collection could be developed.

\section{Methods}

Cone samples were collected during a moderate crop year from trees in 14 stands located throughout most of the productive forested area of Manitoba from $49^{\circ} 19^{\prime} \mathrm{N}$ Lat. $95^{\circ} 20^{\prime} \mathrm{W}$. Long. to $54^{\circ} 31^{\prime} \mathrm{N}$ Lat. $101^{\circ} 30^{\prime} \mathrm{W}$ Long. Usually five dominant or co-dominant trees were chosen in each stand and the tree tops shot off with a 12-gauge shotgun using rifled slug ammunition. All the cones from the top two to three $\mathrm{m}$ were collected.

Sub-samples of 100 cones were selected randomly from each tree. Fifty of these cones were sliced longitudinally and the number of sectioned sound seed on one cut surface recorded. Trees with insect or rust infested cones were rejected; cones from 57 trees proved suitable for analysis. The seed was then extracted from the remaining 50 cones and the cones and seed stored. 


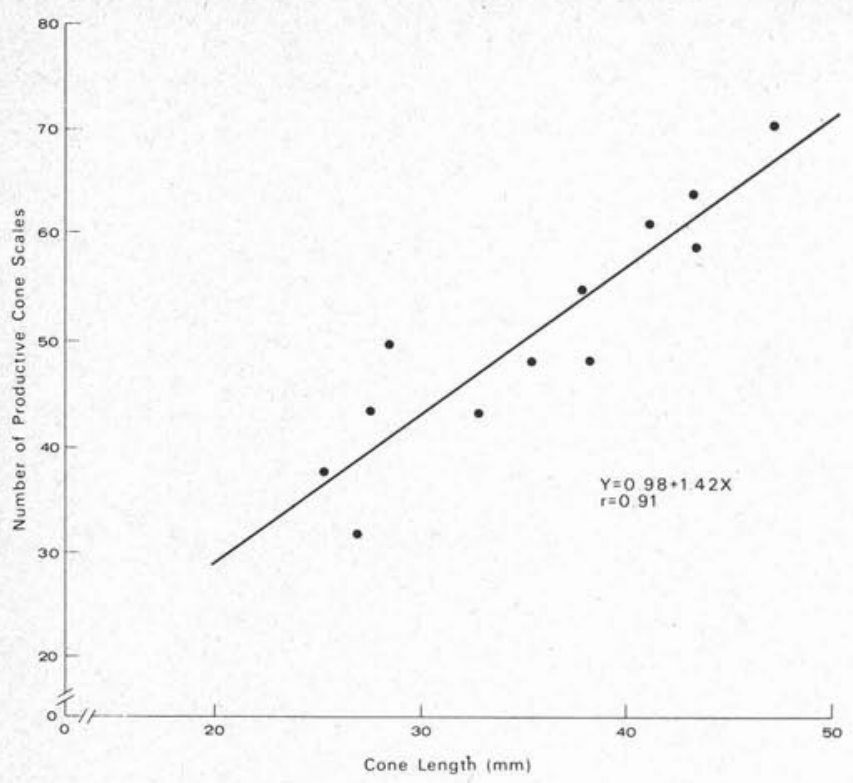

Fig. 1. The relationship between cone length and number of productive cone scales for white spruce cones $(r=0.91)$.

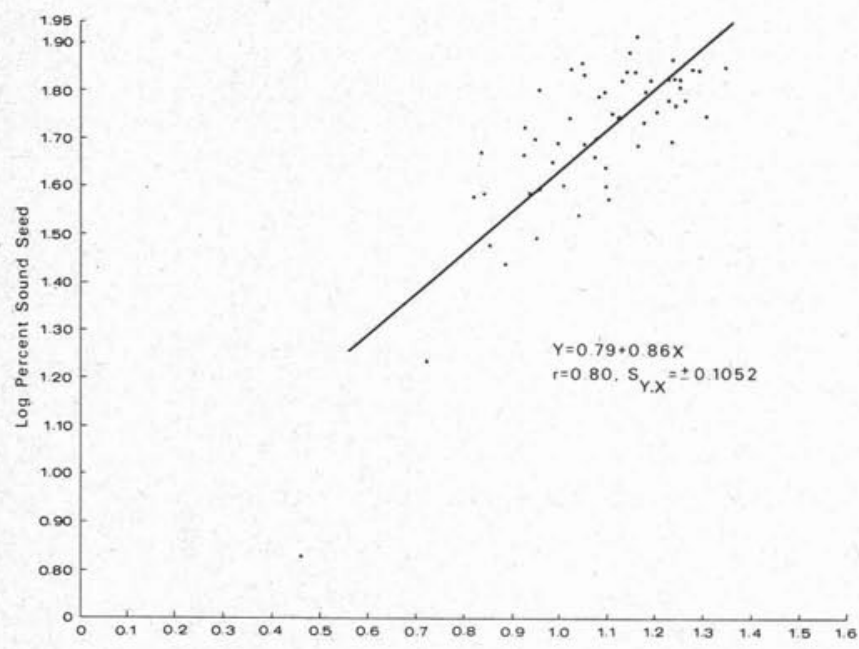

Log(10 $\times$ Number of Sound Seed per $\mathrm{cm}$ of Cone Length)

Fig. 2. Regression of $\log$ per cent sound seed on $\log (10 \times$ number of sound seed per $\mathrm{cm}$ of cone length), $\left(r=0.80 ;\right.$ Sy. $\left.x=0.1052 ; S_{y}=0.0139\right)$.

The kiln dry length of 50 uncut cones was measured for each tree. To determine if cone length affected the potential seed yield the mean lengths were ranked and four trees in each of the 2.0 to $3.0 \mathrm{~cm}, 3.0$ to $4.0 \mathrm{~cm}$ and 4.0 to $5.0 \mathrm{~cm}$ classes selected. Twenty-five cones were then randomly taken from the 50 available cones from each tree and the mean number of productive cone scales determined. A simple linear regression of the mean number of productive cone scales on corresponding mean cone length was made. Analyses of variance was carried out to determine if mean cone length varied between stands and between seed zones (map published in Calvert, undated). A mean cone length with confidence intervals $(P=0.05)$ was calculated for the overall Provincial sample.

Per cent sound seed was estimated for all 57 trees by crushing 500 seeds under magnification.
No attempt was made to determine if the seeds contained an embryo as well as an endosperm.

Linear regression analyses was employed to determine the relationship between per cent seed soundness and the number of sound seed per $\mathrm{cm}$ of cone length. This relationship was used to develop a method of classifying cone crops into three categories by the yield of sound seed (i.e. under $40 \%, 40 \%-60 \%$ and over $60 \%$ ) for the Provincial mean cone length.

\section{Results and Discussion}

The potential seed yield from a cone was closely related to its length. Using mean values for trees, the regression of number of productive cone scales $(Y)$ on cone length in $\mathrm{mm}(X)$ was:

$$
\mathrm{Y}=0.98+1.42 \mathrm{X} \quad \text { (equation 1) }
$$

with the correlation coefficient, $r=0.91$, significant at the 0.01 level (Figure 1). Because of this relationship the independent variable chosen to predict per cent seed soundness was the number of sound seed per $\mathrm{cm}$ of total cone length (i.e. including the non-productive portion of the cone) rather than the mean total count of sound seed per cone.

A relationship existed between per cent sound seed from cones and the mean count of sound seed per $\mathrm{cm}$ of cone length on one half of longitudinally sectioned cones from the same tree. The data required transformation to give a straight line. Several transformations were tried and the one which gave the best fit was the regression of $\log _{10}$ per cent sound seed $(Y)$ on $\log _{10}[10 X$ number of sound seed per $\mathrm{cm}$ of cone length] (X). The latter variable was multiplied by 10 to avoid negative logs in analysis. The equation of the line was:

$$
\mathrm{Y}=0.79+0.86 \mathrm{X} \quad \text { (equation 2) }
$$

with $r=0.80$ and $S_{y \cdot x}= \pm 0.1052$ reflecting good fit to the data (Figure 2). The equation will provide reasonable estimates of sound seed yield from a single tree. The relationship is perhaps most useful when developed into a crop classification system for a single cone length making it applicable to a wider area.

Cones on any one tree proved to be quite uniform in length with a range between trees of $2.52 \pm$ $0.08 \mathrm{~cm}$ to $4.61 \pm 0.16 \mathrm{~cm}$. The maximum range of variation in length was $\pm 0.19 \mathrm{~cm}$. This uniformity is not surprising since the crown zone sampled was restricted and other morphological features of white spruce cones have been shown to be relatively uniform on a tree (Khalil 1974). Analyses of variance showed no statistical difference in mean cone length between seed zones or between stands within a zone. This indicates that there are no consistent geographic trends in cone length and that variation is essentially random. Because of these findings the crop evaluation system would be applicable throughout Manitoba when developed for the Provincial mean cone length (3.52 $\pm 0.12 \mathrm{~cm}$ ) providing adequate sampling is carried out to arrive at this mean.

The crop evaluation system enabling a ranking of qualities was thus developed from equation 2 
for the Provincial mean cone length. The system (Figure 3) was established with three categories. They were: under $40 \%$ (Poor), $40 \%-60 \%$ (Fair) and over $60 \%$ (Good) expected yield of sound seed. The collection of crops in the Poor category is not recommended whereas a Good crop should probably be collected whenever it occurs. It is suggested that a Fair crop be collected only when seed in storage is in short supply. The greatest accuracy of prediction is desired in the Fair category. Statistically, accuracy is highest about the mean value for $X$ (Snedecor and Cochran 1967). In this instance the mean values of $X$ and $Y$ for the Provincial mean cone length was a sound seed count of 4.5 and $54 \%$ respectively ( $S_{y . x}= \pm 0.0139$ ) which would be classified as a fair crop.

Before using the classification system (Figure 3 ) in another part of the range of white spruce one should determine if mean lengths of mature and dry cones for the area in question fall within the $3.52 \pm 0.12 \mathrm{~cm}$ limit. If not, a new curve would have to be developed using the original regression to relate the mean count of sound seed per cone section to per cent sound seed. In this instance the class limits shown in Figure 3 would also change.

The routine use of this system would not require a forester to take samples as large as those taken for this investigation. Seal et al. (1965) recommends for the pines (Pinus L. spp.), larches (Larix Mill. spp.) and Douglas fir (Pseudotsuga menziesii (Mirb.) Franco) in the United Kingdom that five to ten cones from ten trees be sectioned to determine sound seed values. For evaluating crops in British Columbia conifers, including white spruce, Dobbs et al. (1976) suggest that nine cones collected from each of six trees well-distributed throughout the stand be used. Both recommendations give numbers that should be considered tentative and minimum for white spruce. Since this system was developed from cones collected from all aspects of the top two to three $\mathrm{m}$ of dominant and co-dominant trees sampling should be restricted to these crown classes and portion of crown to reduce the chance of bias in the results.

The crop evaluation system would be most useful to the forester in verifying the seed yields expected from abundant cone crops. Situations will occur where a high sound seed yield is indicated but the yield of good seed will be reduced because of poorly developed embryos. Good seeds have yellowish embryos which fill $75 \%$ of the embryo cavity by the end of July (Dobbs et al. 1976). The forester should thus inspect some of the seeds in a cone crop prior to collection to confirm that the crop contains a high proportion of potentially viable seed.

The integration of this method into current monitoring practices of Manitoba and other provinces should not result in much extra effort since seven of the ten provinces now employ some degree of pre-collection seed and come examination to determine seed maturity (Calvert 1973). This process also gives an estimate of level of

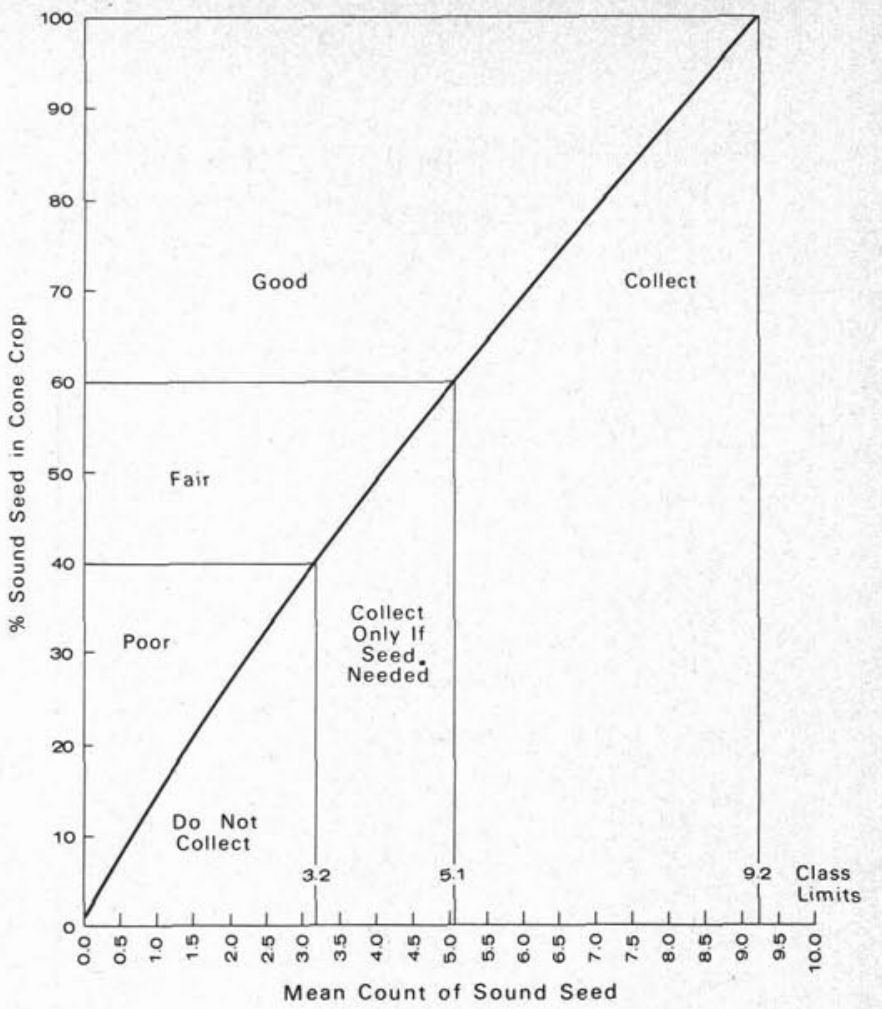

Fig. 3. Classification of white spruce cone crops based on prediction of per cent sound seed in the crop from a mean count of sound seed on one half of five to ten longitudinally-sectioned cones from each of six to ten trees.

damage to the crop caused by insect and disease as well as of poor embryo development which are all important. The information generated by the method would enable the field forester to decide whether seed is available and can be collected efficiently in any given year. White spruce cone collection would thus become a more profitable operation.

\section{Conclusion}

White spruce cones on a single tree were relatively uniform in length but cone length varied between trees. Potential seed yield per cone was found to increase with length. This was taken into consideration when slicing cones longitudinally to determine mean counts of sound seed on half sections by expressing this value as mean count per $\mathrm{cm}$ of cone length. A linear relationship using transformed data was established between yield as per cent sound seed from a tree and the mean number of filled seed per $\mathrm{cm}$ of cone length for the corresponding tree. This relationship was used to develop a cone crop classification system based on mean cone length for the Province of Manitoba.

A three-category system is proposed for use when collectable quantities of cones are available. The system enables the crop to be classified as Good, Fair, or Poor, in potential yield of sound seed. A rating can be determined from the mean count of sound seed on longitudinally sectioned cones from enough trees to arrive at the Provincial mean cone length and by relating this value to a graph (Figure 3 ). It is tentatively 
suggested that a maximum of ten cones from all aspects of the top two to three $\mathrm{m}$ of six to ten dominant or co-dominant trees well distributed throughout a stand be sectioned for this purpose. It is recommended that a Good crop be collected whenever it occurs; a Fair crop should be harvested only when seed in storage is in short supply; a Poor crop is not considered collectable.

The implementation of this method into current evaluation and monitoring procedures used in Manitoba and elsewhere should not be difficult nor should it result in much additional work. If adopted, its conscientious use should make cone collection a more profitable and smoother operation.

\section{Acknowledgements}

The author wishes to acknowledge that much of this work was carried out while he worked for the Research Branch, Department of Mines, Resources and Environmental Management, Province of Manitoba. Appreciaiton is ex- tended to E.K. Morgenstern, A. Carlisle, A.B. Berry and J. Longmuir for their critical reviews of the manuscript.

\section{References}

Calvert, R.F. 1973. Seed procurement and handling: spruce and pine. In Proc. Symp. on Direct Seeding. Dep. Environ., Can. Forest. Serv. Publ. No. 1339:91-101.

Calvert, R.F. Undated. Tree improvement in Manitoba, Research Br., Man. Dep. Mines, Res. and Environ. Mgmt. Info. Series No. 2.

Dobbs, R.C., D.G.W. Edwards, J. Konishi, and D. Wallinger. 1976. Guide to collecting cones of B.C. conifers. B.C.

Forest Serv./Can. Forest. Serv. Joint Rep. No. 3.

Eis, S., and J. Inkster, J. 1972. White spruce cone production and prediction of cone crops. Can. J. For. Res. 2:460-466.

Khalil, M.A.K. 1974. Genetics of cone morphology in white spruce (Picea glauca). Can. J. Bot. 52:15-20.

Meagher, M. 1974. Surveys for seed crops. B.C. Forest Serv. Reforestation Notes 1:16-18.

Seal, D.T., J.D. Matthews and R.T. Wheeler. 1965. Collecting cones from standing trees. Forest Comm. Forest Rec. No. 39.

Spedecor, G.W., and W.G. Cochran. 1967. Statistical methods. lowa State Univ. Press, Ames, lowa.

U.S. Forest Service. 1974. Seeds of woody plants in the United States. Forest Serv. U.S. Dep. Agr. Agr. Handbook No. 450 .

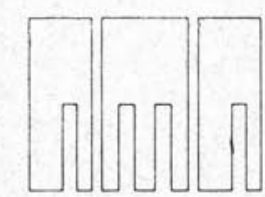

\section{Alan Moss \& Associates Ltd.}

Consultants in Forestry and Forest Industries

\section{Domestic and International}

1420 St. Paul Street

Kelowna, British Columbia V1Y 2E6

Telephone: (604) 763-4811

Cable: Sylva

\section{Woodlot Service Ltd.}

"All Matters Pertaining to Forestry"

GORDON B. YOUNG, B.Sc.F., M.F.

Registered Professional Forester 